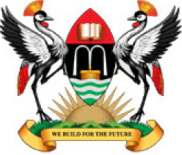

East African School of Higher Education Studies \& Development
Makerere Journal of Higher Education

ISSN: 1816-6822; 4(1) (2012) 1 - 10

DOI: http://dx.doi.org/10.4314/majohe.v4i1.4

(C) The Author(s) 2012

Reprints \& permission: EASHESD

http://ajol.info/majohe

\title{
Role and Nature of Research in Development
}

\author{
Namanji S. , Ssekyewa C. ${ }^{1}$, \\ ${ }^{1}$ Antwerp University, Belgium \\ ${ }^{2}$ Centre for Ecosystems Research [*Corresponding author. E-mail: cssekyewa@ gmail.com]
}

\begin{abstract}
Research and development are two but inseparable aspects that have to be taken into consideration for any country's development agenda to be successful. However, in many less developed countries, the uptake of research in development policy formulation and implementation is inadequate. This paper discusses some of the factors underlying the failure of research to influence policy formulation and implementation in these countries. Starting with a brief discussion of the common paradigmatic and epistemological traditions in research, the paper discusses the challenges involved in development research. Thereafter, it makes a case for a mixed methods approach that is deliberately linked to felt development needs.
\end{abstract}

Keywords: Evidence based policy; Research for Development

\section{$1 \quad$ Introduction}

Research is paramount for meaningful development. Without research development efforts would be baseless. Different forms of research may be conducted according to existing needs and expected results. The more rigorous the research design and careful execution the more accurate and reliable are the results. The purpose of this paper is to make an analysis of the role of research in the development arena. In the first section the meaning of research and development is indicated. This is followed by the importance of research in development. The paper further examined the different approaches used in research, and clearly analyzed epistemological issues in regards to their contribution to the need for valid research results. Conclusions and recommendations are drawn basing on the opinion as regards the need for a mixed approach to development research. In this case meanings of various key terms are given. These include research and development. Other key terms are defined later on in the text. 


\subsection{Research}

Many writers have defined research as a process of looking for solutions to solve a problem that may be existent in a given community or country. For research to be initiated there must have been a problem that becomes the driving force to establish solutions that can solve for that existing problem. Research is the search for new and reliable data. New in the sense that it adds to the existing body of knowledge and reliable in the sense that it is based on facts that can be used for policy formulation.

\subsection{Development}

There may not be a specific definition of development but in reality the term can refer to the effort to make poor people less poor by raising their incomes, and for individuals, to find opportunities to be more productive so as to live better and longer lives, then for an economy as a whole, generating economic growth to raise average incomes and reduce poverty. This description of Development is as an insight from Lecture notes on Economic and institutional Development.

\section{Link between Research and Development}

There cannot be development unless there is a search for knowledge and skills, for having new ideas and means of establishing gaps that may hinder economic, and social progress. This search for knowledge and skills is the one that enables policy makers determine the right kind of policy to formulate and implement for proper development planning.

If there is no proper research, probably proper development policies will not be in place or if proper policies are in place maybe, they would not be implemented to benefit the right stakeholders. That's why research and development are inseparable given that the failure of research may hinder development.

Since research is considered as the systematic process that enables the generation of desired solutions to given problems, it (research) must inform management so that there is use of appropriate policies for sustainable development. Unfortunately, sometimes the approach taken leaves out the would-be implementers of many development projects. This is usually caused by the fact that top officials fund research and thus they set the research agenda. When this happens, research can neither be appropriate nor a source from where management can be well informed to take sound development programs. 
Research in a development arena is a complex reality because it requires different stakeholders, different ideas and a proper environment. In the long run better ideas will bring about economic growth and development. There cannot be sustainable development unless ideas are in place to increase the productivity of capital. Ideas for increasing output must also be researched.

To achieve development, research cannot be done in isolation of those who are well informed about the local setting, in addition to having proper institutions in place to boost investment in physical capital, human capital and technological knowledge (ideas) as indicated by writers from the same link sited above. This is what also Chambers indicated as people paradigm being better than things paradigm that "Many of the errors and failures of development policy and practice have stemmed from the dominance of things paradigm" (Chambers, 2010:13).

The writer shows that top-down standardized approaches and methods were imposed on people from completely different cultures and backgrounds, thus resulting in poor results. That is why progress was realized later on when development programs were shifted to people paradigm.

So for development, a people paradigm will work better than a things paradigm. Ssekyewa (2008) in Scoons and Thompson (1994) indicated that this is participatory and demand driven research. They implied that when all stakeholders are involved, there is a very high possibility of understanding real problems because stakeholders will be informed, and thus appropriate corrective measures would be put in place to solve real problems. In this case one would refer to the African continent as a case where participatory research approaches to research are relevant.

Many so called development projects in Africa have been put in place but without proper research being done to ensure sustainability or cause sustainable development. The major problem causing this is the lack of data and or poor data collection methods.

In relation to that, still Ssekyewa (2008) indicates that many projects have been a cut and paste of the Western world thus making Africa torn apart, implying that "Each development project comes with its own externally advocated technologies often based on development objectives at the source" (Ssekyewa, 2008 1:29-32).

Ssekyewa shows similar observations reported by Paul and Steinbrecher (2003). What usually happens is the failure of these projects to move Africa because the technology used is baseless, not well researched to ensure that it fits the African setting, and therefore leads to no sustainable development but to indebtedness. In the above example therefore, the writer emphasized that

If Africa is to develop sustainably, she must have her own set development agenda based on real African community needs through cross-culture, multidisciplinary and participatory research, appropriate solutions would be 
found. It is these original findings that would form a base for decision making, which would pivot Africa to development (Ssekyewa, 2008:29-32).

Research is a process, and this process is systematic if it has to yield positive results. That is why in their book "finding out fast" Thomas et al. (1998) indicate that the decisions which may be informed by particular investigations are always part of the continuing development of policy so that, it is best to think of policy as a process.

Policies that go through a process and are based on proper findings will always enable proper implementation strategies and thus sustainable development. However, research must be timely to avoid loss intended focus and opportunities. In this case one may consider research to be both area and time specific. Thomas, et al. (1998) continues to give an insight into the need of investigation for development policy and public action.

Investigation should not be done for its own sake but for the sake of informing or influencing the actions of one's own or another agency (Thomas, et al.1998: 15).

This clearly indicates that research should be participatory with all relevant stakeholders having an input into needs identification, priority setting and research planning as well as implementation. Each stakeholder has an influence on the other, hence the need for a participatory approach.

\section{$3 \quad$ Epistemology and Research}

From Kunbur \& Shafter (2007) epistemology is a branch of philosophy which shows the nature of knowledge. These same writers thus labour to indicate that knowledge can be presented in a given perspective and or approaches like empiricism/Positivism, hermeneutics/interpretive approaches, critical theory/critical hermeneutics, and indicating the importance of knowing the nature and constitution of the external world; Ontology.

When research is empirical, there must be reliable data, this data is evidenced just to be sure of its source, so there should be truth or the information must be valid. Therefore, as an epistemological approach, empiricism is defined as "A branch of philosophy which studies the nature and claims of knowledge" (Kunbur \& Shafter, 2006:185-186)

The writers acknowledge this as research approach predicted on an observation-based model for determining the truth or validity of knowledge claims. 
On the other hand, Sumner \& Tribe (2004) define epistemology as a branch of philosophy that is concerned with the nature, origin and scope of knowledge and how we know what we know.

In both definitions, emphasis is put on what we can know, how true is what we know and or how we can validate our knowledge thus indicating a new paradigm of development involving a social -institutional dimension as a key to interaction with and a process of stakeholders' involvement (top-down participation).

Epistemology is thus important in development research because philosophically we are able to provide credibility of our " knowledge and the framework for a process that will produce, through a "rigorous" methodology [...] answers that can be believed to be valid, reliable/replicable and representative/typical." (Sumner and Tribe, 2004:3). This implies that for proper development policies, Epistemology can be highly reliable.

In the development arena, there can be a number of epistemological perspectives but I am going to emphasize positivism and constructivism. These perspectives have differing perceptions of the objectives of academic inquiry and generation of knowledge, as indicated by Sumner and Tribe (2004). However, both are concerned with what constitutes legitimate intellectual goals and practice.

Positivism is then described on the basis of reality and universal truths as being observable. This implies that the researcher cannot in any way influence the results of the research because he/she is expected to be objective, and independent. Positivistic knowledge, therefore, bases on scientific research for the truth and objectivity from scientific experiments using the quantitative approach (Sumner and Tribe, 2004)

On the other hand, constructivism as presented by Sumner and Tribe (2004) in Molteberg and Bargstrom (2002a) is based on the argument that doing realistic research in the world does not happen/exist in isolation of our experiences. We always encounter multiple realities in the research process and these may be intangible, local or specific in nature. Therefore the writers' argument indicates that we cannot base on a single truth in our research to make a description of what exists in the world. That's why, especially when we are doing academic research we need to include people as informants because they have reliable information of what we need to establish.

Given that many policy statements are based on research, there is a need to have reliably done research, with facts and figures to support the policy implementation and this cannot be done without the support of "Sophisticated, informed and inclusive constructions of the world through the interaction of the researcher and the researched". (Sumner and Tribe in Molteberg and Bargstrom, 2004:5). 
Related to the above mentioned importance of constructivism, one would refer to the valley dam project in Eastern Uganda which did not produce any fruits because its setting in the first place was not constructivist. The research that was done to have the valley dams in place was done in isolation of the knowledge of the local people and the Government assumed that these people actually needed the valley dams yet their perception of the same was different. When Government disbursed money to construct valley dams, the inhabitants rejected them and did not allow anybody to do that! These are pastoralists who had the feeling that the aim of constructing valley dams was to take away their cows. So this project did not work moreover a lot of resources had been allocated to it!

Therefore, positivism and constructivism cannot work in isolation of each other. A search for knowledge has to always go through a rigorous process which constitutes all research methods (positivism) but at the same time, this process requires that there is a basic principle that should work and this is looking at the world as a whole and as an open rather than closed entity (constructivism), embarking on participatory research to solve poverty problems is very practical for developing countries.

\section{$4 \quad$ Quantitative versus Qualitative Research}

Methods describe the specific approaches applied in carrying out the research and research can either be qualitative or quantitative. This section gives a description of the two approaches, circumstances under which each of these can be used, limitations of each and why researchers need both of these approaches.

As already discussed from the notion of positivism above, and relating to the work of Kombo and Tromp (2006) quantitative research relies on the principle of verifiability i.e. to confirm, to prove, to corroborate or substantiate, yet the feelings, perceptions or values of the researcher are not taken into consideration, except in as far as discussing generated results vis-à-vis ones views is concerned.

Quantitative research is applicable under circumstances when data is numerical and the analysis must be statistical (how many?), like in case of a need to get frequencies or percentages for explaining findings. From the positivistic point of view as presented by Sumner and Tribe (2004) the basis of this research is a reality and universal truth being observable.

On the other hand, qualitative research involves making a description or an analysis of the behaviour of human beings and their related groups, but putting into consideration those being studied (Kombo and Tromp, 2006). This type of research normally takes case studies. Qualitative research is applicable when 
the subject being studied is not familiar to the researcher (cause-effect) if there is a need to establish relations, the researcher wants to establish a meaning rather than a frequency and a need to establish the unexpected: it is always in depth. This is a constructivism type of research which emphasizes that knowledge is active and creative. It is a social reality in which issues are analyzed in a social process and discursive strategies so that reality is made stable.

However, the two methods are presented as different in a way that they each have different procedures and different epistemological implications indicating that, "every research tool or procedure is inextricably embedded in commitments to particular versions of the world and to knowing that world". (Bryman in Hughes, 2004:452).

This implies that every research is unique-that these two are different paradigms and thus are, therefore, incompatible. The writer presented two versions, first, of why the two approaches cannot work together and second, of why the two can work together.

1. An epistemological version of why the two cannot work together because each is grounded in a different epistemological principle

2. A technical version of why the two can work together because prominence is given to the strength of data collection and data analysis techniques with which quantitative and qualitative methods are associated.

On top of the two versions presented above, Bryman (2004:455) in Hammersley (1996) goes on with a further analysis of the same to present the logic of "triangulation", "Facilitation" and "complementarity" Thus, indicating that the two methods of qualitative and quantitative can work together because quantitative research can be used in qualitative research findings or the other way round, one research strategy is used as an aid to the other research strategy, and the two research strategies are used such that researchers get the details of their investigation. All that may not be achieved unless the two methods are employed.

Two classifications of approaches to quantitative and qualitative (multistrategy) research are proposed as one, being of the priority decision i.e. "How far is the qualitative or quantitative method the principle of data gathering tool?" (Bryman in Morgan, 2004:455).

This implies that the two tools can work hand in hand but the researcher must be clear on which his research is strongly founded, then the other facilitates the process.

The second classification is of "the sequence decision" in other words, which method is coming first or last? Is it quantitative or qualitative? Therefore, the researcher has to be aware of his priority setting such that he/she gives it an emphasis and takes the right direction for his/her research. 
The implication of all these analyses is that the multi-strategy research is good because both methods can complement each other so as to minimize the weaknesses and maximize the strength of each other.

However, one would ask a question: whether qualitative or quantitative research, what constitutes rigor in a research process?

\section{$5 \quad$ Rigor in Development Research}

In their paper on "The nature of epistemology and methodology in development studies", Sumner and Tribe (2004) tackle the issue of epistemology and methodology in development with special care indicating that there is sensitivity of social science methods in development research. This implies that the way we choose to go about research (methods employed) will pose concerns over the validity of that research done, reliability of our data generated, the extent to which results are representative, subjectivity of our research and how we choose to interpret our data.

These can be a problem to the extent of making our research not reliable; implying that the way we choose to do the research should be the bottom line in ensuring validity and reliability of the research. Therefore, from the starting point of identifying a research problem, there must be rigor. Relating to Gutung`s (1967) approach, Sumner and Tribe (2004:7) show that "Each stage leads to the next".

The writers analyze the research process, one step after another and clearly indicate that the process is not an easy one from the start because it gets socially up hazard where the researcher is faced with a problem that is fuzzy, looks for literature on this problem and makes sense out of it.

In addition to that, the rest of the process like research questions should be rigorous and here the writers indicate what a rigorous research question should be that with ability to align the question to a problem, indicate whether similar research has been done already, show clarity on the question, etc.

However this is not an easy task because it requires analytical and critical thinking such that it directs the researcher properly.

Research designs should as well be rigorous because this is the only way to be aware of the kind of answers that the researcher is looking for "qualitative or quantitative or both?" And whether we want "one objective answer or many subjective answers?" (Sumner and Tribe, 2004:11).

This determines the Epistemological methodological approaches to be selected. Important question to ask is whether quantitative methods are more rigorous than qualitative? Summer and Tribe (2002) continue to argue that since there are different settings then there should be different techniques, but 
in their analysis, they indicated that quantitative techniques are more rigorous than qualitative techniques because quantitative methods are perceived as less subjective and more tangible than the qualitative

However this argument may not be valid as is also indicated by white given that when qualitative or quantitative methods are used, rigor will only be determined by the techniques applied by the two methodologies such that badly applied qualitative or quantitative approaches could lead to inaccurate conclusions (Sumner and Tribe, 2004)

What constitutes rigor in research for this context therefore is the methodology of the study employed that relates to how different methods are combined, the step-by-step research approach taken to generate research data that can appropriately, perfectly, reliably and with validity respond to the research question in perspective.

Related to the above, a concrete summary of what rigor is, in the context of development studies and research is indicated.

"[...] rigor in the context of research design consists of the following, of a logical integrated process. The research question leads to a choice of epistemology, leading to a choice of data collection/sources, leading to a choice of data analysis methods [...] techniques needed to answer a particular research question have to be selected with great care..." (Sumner and Tribe, 2004:15)

In light of the above therefore, methods are mixed as appropriate, and research follows a systematic approach; and results are disseminated, indicating how, why, and when such methods were employed. Yet if this research can be appropriately defended, it implies that the research was rigorous and this makes it also valid.

But Maxwell (2005) on "how might you be wrong" emphasizes that methods are not the validity; we can do a rigorous analysis and other rigorous approaches in our researches but they (methods) are not the validity in themselves, rather validity is embedded in the conclusions that we make. The writer indicates that validity is not a product, it is rather relational, and no method can capture validity. Validity is based on evidence, not methods so methods just facilitate evidence. This implies that the methods we choose to use should be rigorous enough such that we are able to draw valid conclusions.

\section{Conclusion and Recommendations}

In conclusion therefore, research and development are interlinked, thus need to be taken holistically. The way we choose to do research depends on our 
epistemological inclination so we can choose to do either qualitative or quantitative research, however a mixture of the two would be more appropriate such that the advantages of each are maximized and disadvantages minimized. For whichever methodology taken, there must be a carefully designed step-bystep approach -rigorous in this sense, to allow for validity of our findings and/or conclusions made. Therefore, it is worth recommending that in all development efforts there is need to identify real development needs, prioritize those needs to address those that are researchable, ensure involvement of all stakeholders at all stages, chose to use the most appropriate methods that would yield meaningful results that stand the rigor and depending on research questions set, go for either qualitative or quantitative research approaches.

\section{References}

Bryman, A. (ed.) (2004). Combining quantitative and qualitative research. Social research methods, Oxford University Press, 450-457.

Chambers, R. (2010). Paradigms, Poverty and Adaptive Pluralism. IDS working paper, 2010 (344): 11-15.

Kombo, K. D. and Tromp, A. L. D. (2006). Proposal and Thesis writing: An introduction. Nairobi: Paulines Publications.

Maxwell, J. A. (ed.) (2005). How might you be wrong. Qualitative research design, an interactive approach. London: Sage Publications, 106-107

Ssekyewa, C. (2008). The role of research in managing sustainable Development in Africa. Journal of science and sustainable development 1(1):29-32.

Sumner, A. and Tribe, M. (2004). The nature of epistemology and methodology in development studies: what do we mean by rigor? Paper prepared for: "The nature of Development Studies" DSA Annual conference, Bridging research and policy, Church house, London, 6 November: 1-22.

Sumner, A. and Tribe, M. (2004). The nature of Epistemology and Methodology in Development Studies: what do we mean by rigor?" Paper prepared for: "Exploring the frontiers in Development Studies Epistemology and methodology", ESRC DSA Postgraduate Training Workshop, Abbey Centre, London, 14 December: 1-229.

Thomas, A. (1998). Introduction. In: Thomas, A., Chataway, J. and Wuyts, M. (eds.) Finding out fast: Investigative skills for policy and development, London, Sage publication, 1-15. 